ment of autonomous parathyroid activity. However, it may also reveal it in those with either prolonged vitamin $\mathrm{D}$ deficiency or previously unrecognised primary hyperparathyroidism, a condition now known to be

1 Finch PJ, Ang L, Eastwood JB, Maxwell JD. Clinical and histological spectrum of osteomalacia among Asians in South London. $Q \mathcal{F}$ Med 1992; 83: 439-48.

2 Corless D, Beer M, Boucher BJ, Gupta SP, Cohen RD. Vitamin D status in long stay geriatric patients. Lancet 1975; ii: $1404-6$.

3 Henderson JB, Dunnigan MG, McIntosh WB, Motaal AA, Henderson JB, Dunnigan MG, McIntosh WB, Motaal AA,
Hole D. Asian osteomalacia is determined by dietary factors wole $\mathrm{D}$. Asian osteomalacia is determined by dietary factors when exposure to ultraviolet radiation is
factor model. $Q \mathcal{F}$ Med 1990; 76: $923-33$.

4 Nellen JFJB, Smulders YM, Jos Frissen PH, Slaats EH, Silberbusch J. Hypovitaminosis D in immigrant women slow to be diagnosed. BMF 1996; 312: 570-2.

5 Sultan AH, Bruckner FE, Eastwood JB. Association between prolonged vitamin $\mathrm{D}$ deficiency and autonomous hyperparathyroidism. $B M \mathcal{F}$ 1989; 299: $236-7$. present in at least $1: 1000$ of the population. Regular screening for hypercalcaemia in populations receiving such vitamin $\mathrm{D}$ repletion regimens is therefore considered to be mandatory.

6 Seshadri MS, Qurttom MAF, Sivanandan R, Samiaman AM. Tertiary hyperparathyroidism in nutritional osteomalacia (letter). Postgrad Med F 1994; 70: 595-6.

7 Krause MW, Hedinger CE. Pathologic study of parathyroid glands in tertiary hyperparathyroidism. Hum Pathol 1984; glands in tertar $772-84$.

8 Davies DR, Dent CE, Watson L. Tertiary hyperparathyroidism. BMF 1968; 2: 395-8.

9 Clements MR, Davies M, Fraser DR, Lumb GA, Mawer EB, Adams PH. Metabolic inactivation of vitamin D is enhanced in primary hyperparathyroidism. Clin Sci 1987 73: $659-64$.

\title{
Meningismus, fever and macular rash as presenting features of the primary antiphospholipid syndrome?
}

\author{
Tim Houghton, Aeron G Davies
}

\begin{abstract}
Summary
We report here, we believe for the first time, the primary antiphospholipid syndrome, presenting with fever, meningismus and skin rash. Serology was positive for antiphospholipid antibodies but negative for antinuclear factor. Such presentations, once meningitis has been excluded, should be screened for antiphospholipid antibodies. If serology proves to be positive, anticoagulation for life should be considered to avoid thrombotic episodes and death due to pulmonary embolism.
\end{abstract}

Keywords: antiphospholipid syndrome, meningismus, thrombosis

The antiphospholipid syndrome is a rare but increasingly recognised clinical entity. It was first described by Hughes in $1983^{1}$ as a clinical condition presenting with widespread venous and arterial thrombosis in the presence of antiphospholipid antibodies. Features of this syndrome are widespread and varied, and include stroke, chorea, migraine, transient cerebral ischaemic attack, ${ }^{2}$ livedo-reticularis, ${ }^{3}$ pulmonary hypertension, ${ }^{4}$ recurrent abortion, ${ }^{5}$ epilepsy, transverse myelopathy, valvular heart disease and ocular ischaemia. ${ }^{6}$ This list will probably be added to, as serological testing for antiphospholipid antibodies is now more general.

We describe the case of a young woman who presented with meningismus, fever and macular rash and who was found to have positive serology for antiphospholipid antibodies.

\section{Case report}

A 21-year-old woman was admitted as an emergency with a 24-hour history of severe generalised headache and photophobia, neckstiffness and rigors. She had a history of three miscarriages and a previous admission two years previously with headache and meningismus, with a normal computed tomography scan of brain.

Examination revealed an ill-looking woman with a pyrexia of $39.2^{\circ} \mathrm{C}$, neck-stiffness, Kernig's sign and a generalised macular erythematous rash. There were no other neurological signs. Initial investigations revealed a polymorphonuclear leukocytosis of $12.1 \times 10^{\%} / 1$ (82\% polys). C-Reactive protein (CRP) was $>150 \mathrm{mg} / 1$ (normal range $1-15$ ). Lumbar puncture and other haematological parameters were normal.

Initially a working diagnosis of possible meningococcal meningitis was made and the patient was commenced on high-dose intravenous benzylpenicillin. The following day she was much better and apyrexial, but she still had the headache and macular rash. In view of the normal lumbar puncture and clinical improvement, the intravenous antibiotics were stopped. She continued to improve and on the day of discharge was well except for a lowgrade pyrexia. Haematological parameters such as white cell count had returned to 


\section{Learning points}

- antiphospholipid syndrome can present in a wide variety of ways and is becoming increasingly recognised

- it appears that any age-group can be affected

- antiphospholipid syndrome can occur as a separate entity without features or serological evidence of systemic lupus erythematosus. This is referred to as the primary antiphospholipid syndrome

- treatment may involve long-term anticoagulation to avoid possible fatal thrombosis

- screening of patients with headaches and meningismus may play a vital role in the future for identifying individuals with this syndrome

normal and the CRP was mildly raised (25 mg/ 1).

Unfortunately, following discharge, she collapsed at home and died. Post-mortem examination revealed the cause of death to be a massive pulmonary embolus. Serology carried out showed negative antinuclear factor but was positive for antiphospholipid antibodies. Examination of central nervous system was normal.

\section{Discussion}

We believe, due to the constellation of various features, such as three miscarriages, recurrent headaches, and fatal massive pulmonary embolism, that this was an example of the antiphospholipid syndrome. The interest surrounding this case lies in the fact that this

1 Hughes GRV. Thrombosis, abortion, cerebral disease and lupus anticoagulant. $B M 7$ 1983; 287: 1088-9.

2 Harris EN, Gharavi AE, Asherson RA, Boey ML, Hughes GRV. Cerebral infarction in SLE: association with antiGRV. Cerebral infarction in SLE: association with anti3 Cardiolipin antibody. Clin Exp Rheumatol 1984; 2: 47-51. Exp Dermatol 1984; 9: 535-44.

4 Asherson RA, Mackworth-Young CG, Boey ML, Harris EN, Hughes GRV. Pulmonary hypertension in SLE: a report of 3 cases. $\mathcal{F}$ Rheumatol 1986; 12: 416-8.

5 Deme GJ, Englert JH, Harris EN, et al. Foetal loss in systemic lupus: association with anticardiolipin antibodies. $\mathcal{f}$ Obstet Gynecol 1985; 5: 207-9. woman presented on two occasions with severe headache and meningismus, with an associated macular rash on the second occasion. Meningismus has been described in patients with systemic lupus erythematosus and positive serology for antiphospholipid syndrome. ${ }^{7}$ However, our patient was positive for antiphospholipid antibodies but had a negative antinuclear factor.

Meningism is usually associated with inflammation of the meninges and hence there is usually a corresponding change in the cellular constituant in the cerebrospinal fluid. In this case the cerebrospinal fluid examination was normal. We are unable to explain the exact mechanism of the meningism in this case, but presume that meningeal microvascular thrombosis played a key role. A review by Hughson $e t$ al concluded that 'the cerebrovascular changes of the antiphospholipid syndrome are derived from a chronic thrombotic microangiopathy'. ${ }^{8}$

This is the first case reported in the literature describing an association between headache, meningismus, macular rash and a positive antiphospholipid antibody. In view of the tragic and fatal event in this case we wish to highlight the possibility that meningismus and the presence of macular rash may be a further manifestation of the antiphospholipid syndrome. We suggest that patients presenting with a meningitic-like illness with macular rash and normal lumbar puncture, should be screened for the presence of antiphospholipid antibodies. Such patients may need serious consideration for appropriate anticoagulation therapy to prevent possible fatal complications.

6 Hughes GRV, Harris EN, Gharavi AE. The anticardiolipin syndrome. 7 Rheumatol 1986; 13: 486-9.

7 Watanabe T, Satoh MAT, Hayashi M, Otla Y. Stroke and Watanabe T, Satoh MAT, Hayashi M, Otla Y. Stroke and
meningitis in a case of SLE with antiphospholipid antibodies. Acta Paediatr Ypn 1993; 35: 423-5.

8 Hughson MD, McCarty GA, Sholer CM, Brunback RA. Thrombotic cerebral arteriopathy in patients with the antiphospholipid syndrome. Mod Pathol 1993; 6: 644-53. 